\title{
HOW ARE PUBLIC SPACES SUSTAINING CULTURAL IDENTITIES IN THE CONTEXT OF CHINA'S INCREASINGLY GLOBALLY FOCUSED URBAN DEVELOPMENTS: USING A CASE STUDY OF PUTUO IN SHANGHAI
}

\author{
Hee Sun (Sunny) CHOI \\ Choi-Comer Architecture and Urban Design, Urban Design Lab, Mews House, 86 Becklow Road, London, \\ W12 9HJ United Kingdom of Great Britain and Northern Ireland \\ E-mail:hee_sun26@hotmail.com
}

Received 12 January 2015; accepted 10 December 2015

\begin{abstract}
This paper explores what it means for a public space to embody the city within rapid urban change in contemporary urban development and how a space can accomplish this by embracing the culture of the city, its people and its places, using the particular case of Putuo, Shanghai in China. The paper employs mapping and empirical surveys to learn how the local community use the act of communal dance in everyday public spaces of this neighborhood, and seeks not to find generalizable rules for how humans comprehend a city, but instead to better understand how local inhabitants and their chosen activities can influence their built environment. The findings from this emphasize the importance to identify how public spaces can help to define cities with China's emerging global presence, whilst addressing the ways in which local needs and perspectives can be preserved.
\end{abstract}

Keywords: public space, cultural identity, sustainability, local community.

\section{Introduction}

Space is a material product, in relationship to other material products-including people who engage in historically determined social relationships that provide space with a form, a function, and a social meaning (Castells 1972: 152).

Twenty years ago Sorkin et al. (1992) argued that the quality of public space was in inexorable decline. How has the emergence over the last thirty years of mobile and wireless communications networks impacted on the usage and physical act of communication within public space? Although, public life appears to be blossoming again on the streets and squares of our cities, increasingly more of daily life within public space takes place publicly, but within a private sphere, through the communication and entertainment options provided by phone, tablet and laptop. As the information society is providing new meaning and significance to the city as a meeting place, there are clear signs that the city and city spaces have been given a new and influential role as civic space and forum. Townsend (2001) and others have highlighted how the temporal quality of wireless and mobile networks can lead to a reconfiguring of the spatial and visual qualities of the city, thereby questioning the nature of city infrastructures and how public space is formed, both physically and socially.

Given this context and the increased prevalence of digital dependency, together with the ambitions of urban development that are geared towards globally and locally created new forms of urban spaces, are the opportunities thus diminishing to bring authentic meaning to public space via communal physical interaction and direct community engagement? If so, how is this affecting the creation and sustenance of a particular sense of place and attachment within public space and urban society?

This paper uses the example of communal exercise and dance within the rapidly expanding and increasing hi-tech city development of China as a means to assess the impact of direct interaction within public space and the local community. Although Chinese cities are experiencing an intense period of growth and change, an instance of usage that is proving resistant to this change is the way in which urban inhabitants continue to come together several times a week in arranged dance sessions in public space. The urban district of Putuo 
in Shanghai, China is used as a particular example in how the local population makes use of public space for collective dancing in this way. This district is particularly relevant and useful for this study as it combines an industrial past with rapid growth focused on hi-tech industries, an increasing population of economic migrants and a varied local community that is both open and resistant to change.

The aim of this paper is thus to reconcile this locally informed community pastime within the context of the multi-national companies and global aspirations for this new urban district, in an effort to better understand the balance that is reached between them in a single urban public space. Moreover, this paper seeks not to find generalizable rules for how humans comprehend a city, but instead to find out what elements of their surroundings were important components to their daily lives. A key element of the argument here is that the localization of strategic components of globalization in these cities means that the disadvantaged can engage in at least one moment of the trajectory that is today's global economy and global power.

From these findings, the paper aims to represent the importance of identifying how urban public spaces can help to satisfy the appetite for emerging global presence, and at the same time address and preserve local needs and perspectives.

\section{Research methods}

The research employed empirical studies including site observation, interview questionnaires, a focus group meeting and field surveys carried out from September to November, 2013, together with a review of related government and development policy literature and proposals from secondary sources. Using William Whyte's "The Social Life of Small Urban Spaces" (1961) as a key precedent, these research methods provided a means of gaining a deeper insight into practical questions and issues relating to public life in public space. The data was gathered during the spring and summer of 2013 at the Hangin Shopping Mall public plaza in Putuo. This paper focused primarily on the triangulation of data from three instruments: (1) A survey of inhabitants daily routine, including identification of activities hour-by-hour, and key locations during one typical day; (2) dancer maps to indicate this usage of the public spaces within the neighborhood; and (3) a survey of questions for participants. 21 semi-structured interviews were carried out with local residents and users. The questions asked through interview and survey were designed to help understand whether the participants were local to the area and if so how long they had lived there, their occupation, how the dan- cing is arranged, why they attend and what qualities of the public space and the urban transformation taking place made it an attractive place for them to do so.

\section{The urban and social context of public space}

In Collage City, Rowe and Koetter (1978) describes the contemporary urban environment as a collage of shifting polarities capable of supporting "a reality of change, motion, action and history".

The public spaces of the pre-modern yielded to contextual conditions with a relative modesty, whereas the modern produced isolated masses calling attention to themselves. The former was inefficient, contingent and chaotic, whereas the latter was efficient, planned and ordered. In the wake of these two traditions, and borrowing from Claude Levi-Strauss, it can be argued that public space must find its place "between structure and event, necessity and contingency, the internal and the external" as a combination of planning and appropriation.

Public space in Chinese classification includes "all piers, thoroughfares, streets, roads, lanes, alleys, courts, squares, archways, waterways, passages, paths, ways and places to which the public have access either continuously or periodically, whether the same are the property of the government or of private persons" (Shanghai Putuo 2013).

Public space may be gathering spot or part of a neighborhood, downtown, special district, waterfront or other area within the public realm that helps promote social interaction and a sense of community (Carmona, Tiesdell 2007). Possible examples may include such spaces as plazas, town squares, parks, marketplaces, public commons and mails, public greens, piers, special areas within convention centers or groups, sites within public buildings, lobbies, concourses, or public spaces within private buildings. As with all categories of Great Places, it is important to identify what sets a space apart from others spaces so as to qualify it for a great spaces designation (Low 2006).

Looking at the city of Shanghai in detail, the city grew in the pre-industrial era and then was fundamentally transformed following the Maoist model of urbanization. This model included strict migration control, a comprehensive residential work-unit system, a highly developed bureaucratic allocation system, an emphasis on production rather than consumption and a relatively egalitarian distribution system. The powers that define urbanization in China are making a gradual transition from central planning to market forces, with an increased focus on developments for consumers as disposable incomes rises.

In addition to the development power of consumption. Mommaas (2004) noted a shift ofculture- 
centered urban regeneration strategies from providing venues for or organizing spectacular events of consumption to a more fine-tuned policy of creating spaces and milieus for cultural production. A key policy from the Shanghai Municipal Government (Zheng 2010) acknowledges the role of creative redevelopment, with the introduction of 75 Creative Industry Clusters to encourage a bottom up approach to creative use and re-use. In order to assess this dvelopment it is important to better understand how locally informed community pastimes continue to feed change and an urban evolution that creates new forms of city living within the context of the contemporary post-modern city.

Since urban public spaces are a crucial part of the life of the city, it is equally crucial that we understand how they currently function. In order to make a specific assessment and as a method for more stimulating and engaging urban design. there are different types of urban space that it is necessary to define, in order to indicate which particular ones this paper will address. Lloyd and Auld (1989) provide a useful framework for this form of assessment of urban spaces, dividing them into three categories: private, parochial, and public. Private spaces are those that are "characterized by ties of intimacy among primary group members who are located within households and personal networks." Parochial spaces can be considered neighborhood spaces, those that retain a "sense of commonality among acquaintances and neighbors who are involved in interpersonal networks." (Ibid.) "Public" spaces are those that are inhabited by individuals who are "personally unknown or only categorically known to one another." (Ibid.)
Having urban spaces that reflect the city and its inhabitants is critical to its livability. These spaces make residents proud of their city and make it a more enjoyable place to be. They also foster a sense of community among inhabitants by dismissing social differences and "assuming that all participants share a common experience and common values" (Lloyd, Auld 2003: 346). These spaces also attract people from outside the city, who want to take part in the energy of urban life. Urban spaces that are reflective of the city actually become microcosms of the city, taking on its characteristics and articulating them. Through this articulation, and as Rowe and Koetter argued in Collage City (1978), the city and urban space begin to reinforce the importance of their mutual reliance on one another, with the interplay between the two crucial for the creation of great urbanism.

\section{Public space within the context of the development of the Shanghai district of Putuo}

One particular urban district that demonstrates well this transition from old to new is Putuo in Shanghai, a newly urbanized area created by state-owned enterprises and new businesses as a gentrification of a former industrial area. However, alongside these new developments retired industrial workers remain in residence in dilapidated temporary housing on vacant sites, who have been joined by low income economic migrants entering the city with the aim of prospering from this growth. Putuo is situated in the northwest part of Shanghai (Fig. 1) and covers an area of 54.99 sq. $\mathrm{km}$, with a registered population of 843,600 (Map of Shanghai 2014).

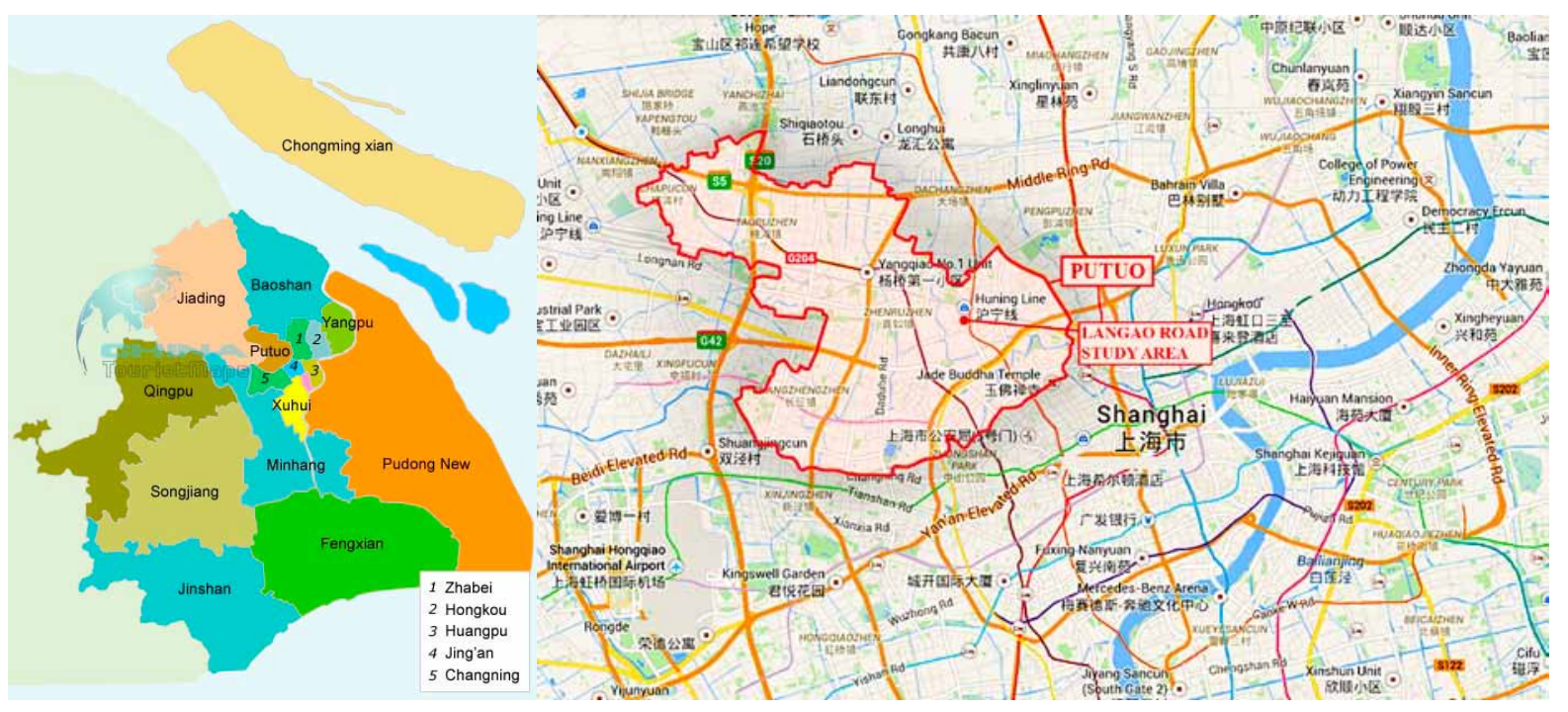

Fig. 1. Map of Shanghai that indicates the central location of Putuo district ((left) Shanghai Putuo 2013(right) created by the author according to Map of Shanghai... 2014) 
To consider the character of the built environment within this case study area of Putuo, this currently consists of a complex mix of architectural typologies. Large development sites sit alongside crowded streets and older apartment blocks of 8-12 storeys (Fig. 2) that house both displaced local residents and an increasing number of economic migrants. As a result, new development complexes with high-cost in-house dining and entertainment provisions geared towards hotel guests and new office workers, sit alongside roadside diners and shops that cater for lower income residents. The gentrification and transformation of Putuo is being actively engineered by the Municipal Government via preferential policies to encourage development and growth through tax incentives (Zhong 2014). These incentives are targetted towards "high-tech" firms in particular, via central planning and market forces, with an increased focus on developments for consumers as disposable incomes rises. Considering this, the spatial logic of exercising centralized control and management risks an inbalance between the capitalist class and the labour force that remain in residence. The aerial view in Figure 2 shows how this imbalance can be operationalized; the newly developed shopping mall (completed 2010) and retail / restaurant buildings sit adjacent to the metro entry point, together with two high rental office complexes and two five star hotel towers, surrounded by government constructed housing for the low income labour force to the south, east and west. To the north is Pin Zuo Guo Ji, a newly constructed private gated residential development (2012) marketed towards higher income residents.

This new production of global power and market force raises questions as to whether the new creative use of public space by local residents in squares, parks, and public open spaces is being encouraged or manipulated by this growth-led government policy towards hi-tech industrial clusters. Or whether the local population that are living through this growth, or providing for it, are having a chance to engage their needs and demands into the physical form of influence over public space.

The site survey of the area of Figure 2 included particular focus on the nature of the open spaces that have been provided within this neighbourhood, and whether the framework of definitions introduced earlier from Lofland (1989) for private, parochial or public could apply. The study commenced with a review of the masterplan area for Figure 2, which concluded based on the size and position of the public spaces relative to adjacent functions the classification of pu-

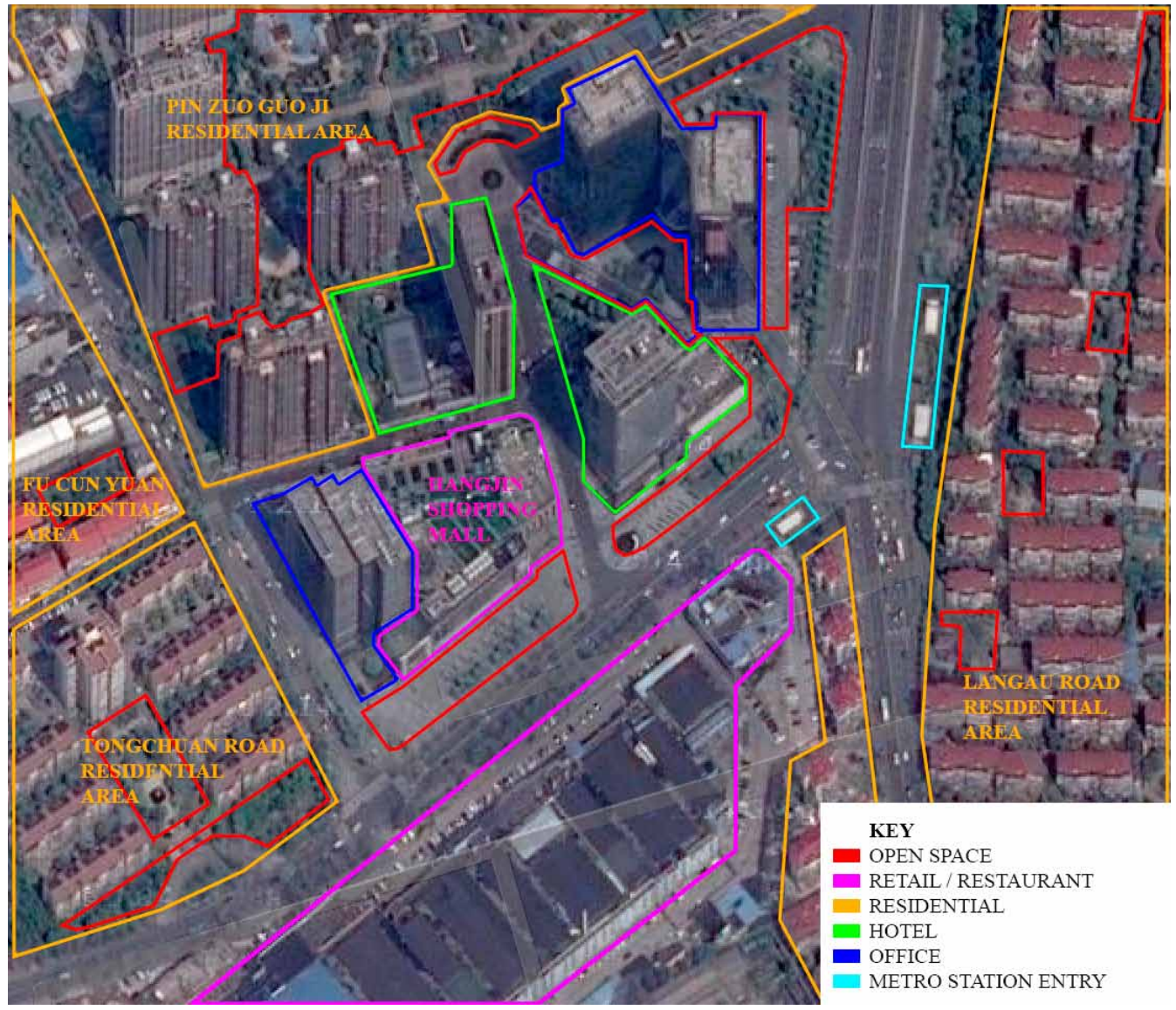

Fig. 2. Aerial view of Putuo District adjacent to Langao Road Subway Station, Shanghai (Aerial view... 2014) 


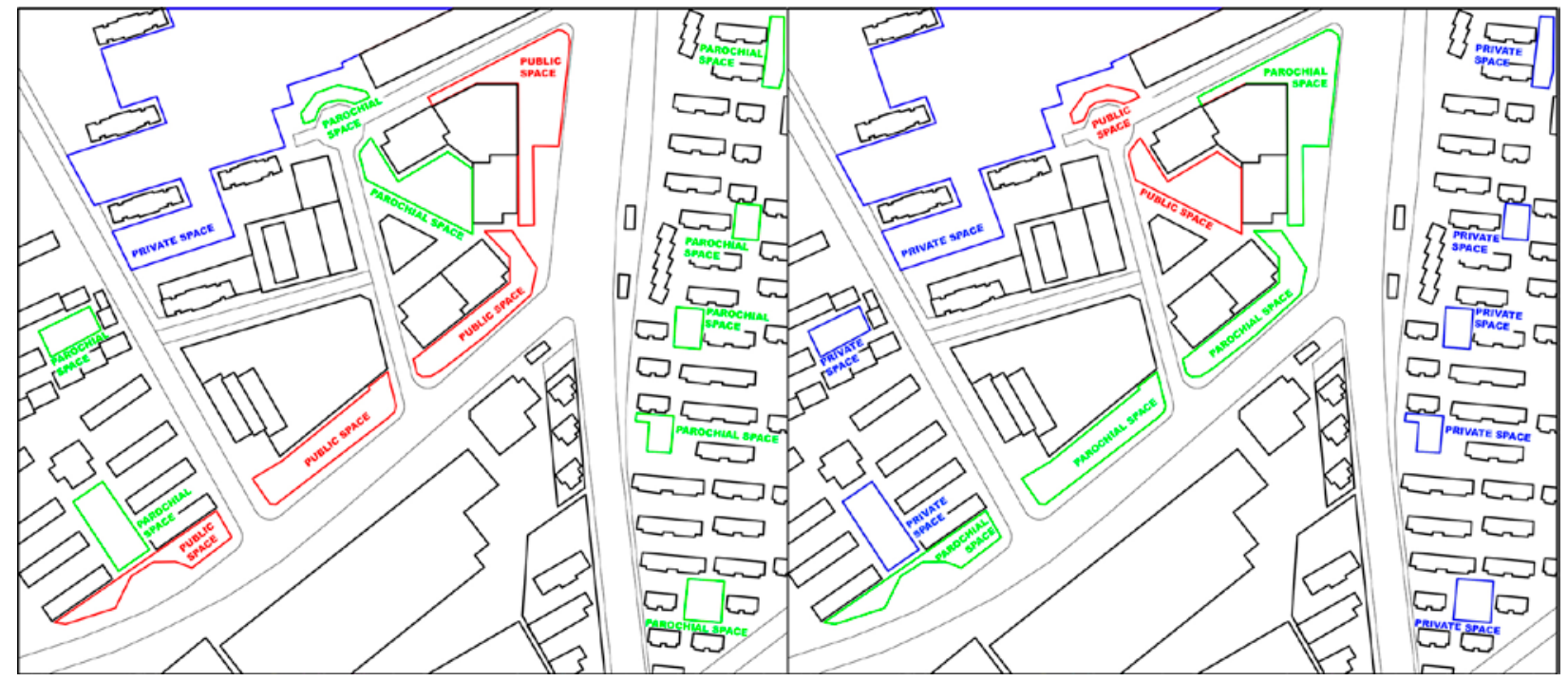

Fig. 3. Left: Assessment and classification of public space based on masterplan review; Right: Assessment and classification of public space following site observation

blic space indicated on the left in Figure 3. The spaces along the main road adjacent to the new commercial development can be classifiable as public (ie inhabited by individuals unknown or only categorically known to each other), the public spaces within the interior of the private gated residential area can be classified as being more private in character (i.e. characterized by ties of intimacy among primary group members), whilst the open spaces within the housing areas and the "interior" space within the new development area can be classified as parochial (i.e. a neighbourhood space that has a "sense of commonality among acquaintances and neighbours who are involved in interpersonal networks"). It can be presumed that this arrangement and hierarchy of spaces was the outcome intended and hoped for by the municipal planners.

However, site observation proved these classifications and planning predictions to be largely incorrect (see the right hand map of Figure 3). Those spaces directly adjacent to the main road and commercial space that were predicted and planned to be public in character, are in fact parochial. The local community are appropriating these public spaces and they have developed a semi-private atmosphere as the chosen location for community gatherings for organised dancing and other informal events, with a sense of commonality and closer ties among the acquaintances and neighbours who gather there. The survey supported this observation with those who were dancing generally living very locally, in the surrounding residential areas of Tongchuan, Fu Cun Yuan, Langao Road and the private gated Pin Zun Guo Ji development.

A survey of those participants in these dance gatherings outside Hangjin Mall highlighted the particular qualities of this public space for their parochial, semiprivate functions are as follows:

1. The public plaza is of a reasonably large size and brightly lit.

2. The surrounding seating and landscaped area are good for breaks during and after dancing.

3. Some distance from the residential area meant that the loud music was not an issue for other residents.

4. The adjacent shopping mall is convenient for shopping, restaurants and bathroom facilities for those dancing and their friends and family.

These characteristics are highlighted in the following montage (Fig. 4).

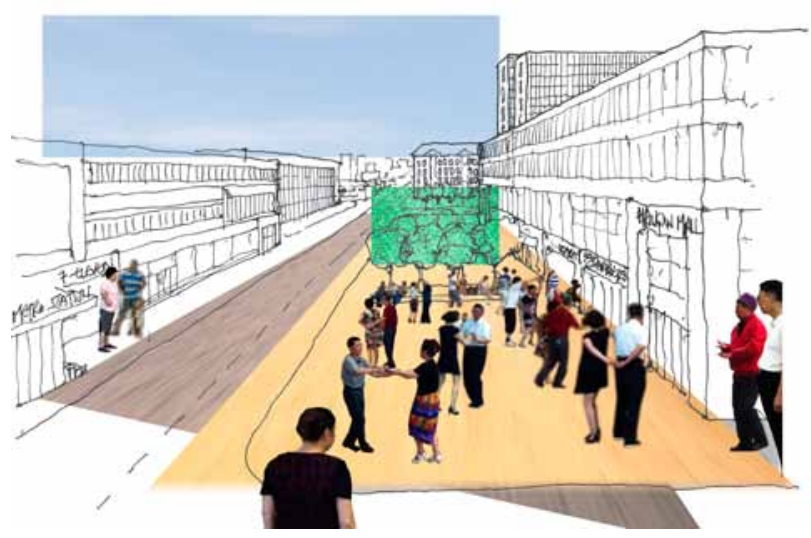

Fig. 4. A collage of images forming a visual characteristics of community usage of public space in Putuo, embracing the sustenance local identity and create new place identity in new place making

Note: Based on the different design approaches of public, parochial, and private space in new place making of Putuo district. 
Figure 4 presents a views of physical urban morphology with building forms and infrastructure, and users' particular activities within the public open space which faced to the main road of the Putuo district. Although decision makers and planner/designers established a range of different kinds of urban open space and infrastructure in physical built form, in order to attract multinational investors and tenants, the findings represent the contrasting ways in which the local users and residents make use of these open spaces. They illustrate the vitality and liveability of the users and residents' desires and needs in the establishment of local identity in place making, with this particular case of Putuo significant also for how this can be established within the wider context of contemporary Chinese urban development. These findings offer an alternative reading and term definition for public, parochial and private open space, and how this can sustain social and cultural identities in the context of contemporary place making for Chinese urban development.

Also as shown in Figure 3, the site observation indicated that the "enclosed" space within the new development does not have any of the parochial characteristics, and is in fact more public in character, and the smaller courtyard spaces within the residential areas, presumed and planned to be parochial in character are be used in a very private, uninviting way. For instance, those neighbours directly adjoining these smaller courtyard spaces use the space to hang and dry their laundry and dry vegetables.

An extension of this practical assessment of the definitions of public open space originally put forward by Lofl and Auld, would be to question to what extent does this analytical and methodological dilemma associate with the tension between localising and universalising conceptualisations of the terms of public open space? And how can this redefine the value of social contents with physical design, in relation to the fabric and scale of urban space and how it is occupied and used.

The redevelopment of this neighbourhood in Putuo shows elements of what Ash Amin has described as "telescopic urbanism", a form of intervention that relies on rapid implementation of buildings and spaces that have little to do with the scale, texture, and fabric of existing neighbourhoods and communities. The new commercial and tourist enclave appears disconnected from its residential contexts, with the development taking place as a process of "rupture" rather than "accretion". The occupation of the public spaces constructed with this new development can be interpreted as the local communities attempt to reconnect with this "rupture" and restore some linkage and local character.
The theoretical and practical review within this paper has highlighted how the definition and operationalization of public space can be redefined both by the physical locations and also the patterns of behavior that occur in those locations. These dynamic social formations create a physical urban "metonymy" - landscapes where people are prompted to have an active role and participate, providing them with a sense of ownership, a site of social activity and an expression of society (Castells 2004; Choi 2015). The survey of participants in the organised dance supported this theory, with one participant commenting that "this public space is good and it is great that we can gather together and dance. This area becomes more vivid". A number of respondents commented how the dancing was a very good way to meet people and socialise with the local community, including one who said "I feel I can relax when I dance here. It's meaningful to me".

In light of these findings from the users' daily pattern of social interaction and usage of the built environment in Putuo, it is clear that this social network is contextualized and localized within the physical, tangible layers of the city. What is illustrated is how, as Gadanho has argued (2014), the "space can make a difference in offering the powerless the possibility of making presence. The street can, thus, be conceived as a space where new form of the social and the political can be made, rather than a space for enacting ritualized routines". The urban "community" is being augmented by networks of interpersonal ties that provide sociability, support, information, a sense of belonging and cultural and social identity. In a related study of urban dancers in Beijing by Chen (2011), it was observed that these dancers were open to the growth and modernisation of the city, and looked forward to the changes in their neighborhood that would help bolster China's emerging global presence. These preferences are consistent with Bentley's et al. (1985) vision for a design ideology in which local identity is rooted but future oriented. The location-specific communication between individual users provides the local public spaces in Putuo with a sustained but evolving contextualized and territorialized urban character, based on daily patterns of usage and orientation.

In summary, the way in which the discussion and findings consider how public spaces are sustaining cultural identities in the context of China's increasingly globally focused urban development, using a case study of Putuo in Shanghai, can be highlighted as follows:

- Driven by a demand for rapid urban transformation, it has been feasible to characterize the majority of recent South East and East Asian urban developments as market-driven and consequently 
resulting in a degree of homogeneity in their built form patterns and a lack of concern for sustainable public sphere and building practice. This has contributed to a degradation of both regional culture and civic society.

- The findings from the users' daily pattern of social interaction and their usage of the built environment in Putuo, Shanghai, define how this social network is contextualized and localized within the physical, tangible layers of the city. Rather than a space for enacting ritualized routines, the street can be conceived as a space where new social and political forms can be made. The urban "community" is being augmented by networks of interpersonal ties that provide sociability, support, information, a sense of belonging and cultural and social identity.

- With the location-specific communication between individual users in the public spaces in Putuo they can be interpreted as the hinge between the built environment and society, operating between order and chaos, the artificial and the natural. This dichotomy is represented in a sustained but evolving contextualized and territorialized urban character, based on daily patterns of usage and orientation.

- Considering the character of the principle public space in Putuo in more detail, with its position between commercial space, a main highway and mass transit station has the physical and locational characteristics of an outward-looking public space, following the definitions from Lloyd and Auld's (2003) for private, parochial or public space. However, site observation has shown how this space has developed a semi-private atmosphere as the chosen location for community gatherings for organised dancing and other informal events. Hence it is closer in atmosphere to parochial space, with a sense of commonality and closer ties among the acquaintances and neighbours who gather there. This shows that physical urban spaces and public spaces are not always predictable in their function and usage.

Considering this summary of highlights, one challenge is to analyse what happens in those spaces and what operations (analytic, of power, of meaning) take place there. Current conditions in global cities are creating not only new structurations of power but also operational and rhetorical openings for new types of actors and their projects. A key element of the argument here is that the localization of strategic components of globalization in these cities means that the disadvantaged can engaged at least one moment of the trajectory that is today's global economy and global power (Sassen 2014: 42).

\section{Conclusions}

To better understand how public spaces are being sustained as cultural identities in the context of China's increasingly globally focused urban developments, this case of Putuo in Shanghai represents the power that community life has to animate and influence government-led rapid urban development. Mapping and empirical surveys represent how the local community spend their free time in the act of traditional communal dance in everyday public spaces of this neighborhood, an activity that on the surface appears difficult to reconcile with the global aspirations and design intent for this newly developed neighbourhood.

Also there are lots of new population of economic migrants and a varied new and old local community that are both create new urbanized space as global economic power with government-let control in Putuo development in order to be new hi-technology industrial cluster area. However, the occupation of public space revealed as the local community striving for spatial justice and a bottom-up attempt at community selfarrangement. And it could addressed the importance of how urban public spaces can help to satisfy the appetite for emerging global presence, together with preserving local needs and perspectives. This evolving terms of "public open space" thus represented its meaning within the rapid urban development as rooted but future oriented and truly operationalized space for everyone in built environment, not reluctantly left over by physical development and by new life style with new technology infrastructure. When cities are evolving so rapidly, as in the case of China, an interesting aspect is how the pre-existing community and culture continue in parallel with this, and engage with it. The dancers in Putuo offer an example of this, in how the traditional pastimes of the local residents are continuing.

In this way, new urban environments are being engaging and appropriated by local residents to suit their needs, perhaps not in the way the developers intended, but rather, as Gadanho has argued (2014), in the way in which the "space can make a difference in offering the powerless the possibility of making presence. The public space can, thus, be conceived as a space where new form of the social and the political can be made, rather than a space for enacting ritualized formed". The urban "community" is being augmented by networks of interpersonal ties that provide sociability, support, information, a sense of belonging and cultural and social identity. 
This paper, using the particular example of the neighbourhood study of Putuo, represents the extent to which traditions of thinking about cities from the perspective of urban modernity needs to be reconsidered. It provides an example of how the global aspirations for the evolution of a neighbourhood and its open spaces will not produce the preferred plan of the Municipal Government if they are not supported by the local community. The community occupying public space for collective dance is an example of how these local residents can empower themselves and assert their own ambitions for the usage of the open spaces within their community.

Contemporary urban design and development in China has come a long way in a very short time. In response to this rapid urban change, local citizens are seeking to redefine their role in counterbalancing the growing economic inequality within the urban neighbourhoods in which they live, with public spaces that are geared towards their own needs alongside the developer's need for profit and the planner's desire to compete on a global stage. Given this, the next step for designers and planners could be to further define how the design and identity of public space can respond to these functions and uses (Francis 2003), such as in the case of Putuo.

In conclusion, particular forms of community engagement can help to define contemporary cities in flux, and act as a counterpoint to the planned policies for growth, which can be more generic in character. This has implications not just for urban development in China, but more broadly in how to sustain cultural and social identity in urban space through evolving form and function. Although these inhabitants seem to be defying their local government's desire to modernise, an important lesson is not in how people's activities relate to the existing community, but in how these ongoing activities and identities can inform the design identity of the next generation of urban environments.

\section{References}

Aerial view of Putuo District adjacent to Langao Road Subway Station, Shanghai. [online] 2014, [cited 01 December 2014]. Available from Internet: https://www.google.com.hk/maps/ place/Langao+Road/@31.2576894,121.4143365,642m/data= !3m1!1e3!4m5!3m4!1s0x35b26fb81124dad3:0xb8f4f98b0db $9960 \mathrm{e} ! 8 \mathrm{~m} 2 ! 3 \mathrm{~d} 31.256222 ! 4 \mathrm{~d} 121.421793$ ?hl=en

Bentley, I.; McGlynn, S.; Smith, G., et al. 1985. Responsive environments. Oxford, UK: Elsevier.

Carmona, M.; Tiesdell, S. 2007. Urban design reader. Oxford, UK: Elsevier.

Castells, M. 1972. The urban question. London: Edward Arnold.

Castells, M. 2004. The network society. A cross-cultural perspective. Los Angeles, US: Edward Elgar Publishing.
Chen, C. 2011. Grandma's world: mapping dancers in Beijing, in Proceedings of the 42nd Annual Conference of the Environmental Design Research Association, 25-28 May 2011, EDRA 42 Chicago, IL, USA.

Choi, H. 2015. Local identity in the form-production process, using as a case study the multifunctional administrative city project (Sejong) in south Korea, Urban Design International 20(1): 66-78. http://dx.doi.org/10.1057/udi.2013.38

Francis, M. 2003. Urban open space: designing for user needs. Washington, London: Island press.

Gadanho, P. 2014. Uneven growth: tactical urbanisms for expanding megacities. NY: The Museum of Modern Arts.

Lloyd, K.; Auld, C. 2003. Leisure, public space and quality of life in the urban environment, Urban Policy and Research 21(4): 339-356. http://dx.doi.org/10.1080/0811114032000147395

Lofland, Lyn H. 1989. The morality of urban life: the emergence and continuation of a debate, Places 6(1): 18-23.

Low, S. M. 2006. The erosion of public space and the public realm: paranoia, surveillance and privatization in New York City, City \& Society 18(1): 43-49. http://dx.doi.org/10.1525/city.2006.18.1.43

Mommaas, H. 2004. Cultural clusters and the post-industrial city: towards the remapping of urban cultural policy, Urban studies 41(3): 507-532. http://dx.doi.org/10.1080/0042098042000178663

Rowe, C.; Koetter, F. 1978. Collage city. Cambridge, Massachusetts and London: MIT Press.

Sassen, S. 2014. Uneven growth: tactical urbanisms for expanding megacities. NY: The Museum of Modern Arts.

Map of Shanghai that indicates the central location of Putuo district [online]. 2014 [cited 28 October 2014]. Available from Internet: https://www.google.com.hk/maps/place/Sh anghai,+China/@31.2231337,121.441546,13z/data =!4m5!3 m4!1s0x35b27040b1f53c33:0x295129423c364a1!8m2!3d31. $230416 ! 4 \mathrm{~d} 121.473701$ ?hl=en

Shanghai Putuo. 2013. The Putuo District Development and Reform [online], [cited 06 September 2013]. Available from Internet: http://english.shpt.gov.cn/government/organization/

Sorkin, M. 1992. Variations on a theme park: the new American city and the end of public space. USA: The Noonday Press.

Townsend, A. M. 2001. Network cities and the global structure of the Internet, American Behavioral Scientist 44(10): 1697-1716. http://dx.doi.org/10.1177/00027640121957998

Whyte, W. H. 1980. The social life of small urban spaces. New York: Project for Public spaces.

Zheng, J. 2010. The "entreprenuerial state" in "creative industry cluster" development in Shanghai, Journal of Urban Affairs 32(2): 143-170. http://dx.doi.org/10.1111/j.14679906.2010.00498.x

Zhong, S. 2014. Production, creative firms and urban pace in Shanghai, Culture Unbound: Journal of Current Cultural Research 4: 169-191.

\section{HEE SUN (SUNNY) CHOI}

She is Dr, Completed her PhD in Urban Design at Oxford Brookes University. Sunny has published a large number of publications and regularly presents papers in international conferences. Research interests: digital infrastructure, cultural identity and environmental sustainability. 